\title{
The effect of humoral and cell-mediated immunity in resistance to systemic serratia infection
}

\author{
Y. KUMAGAI, K. OKADA and Y. SAWAE \\ First Department of Internal Medicine, Faculty of Medicine, Kyushu University, 3-3-1, Maidashi, Higashi-ku, Fukuoka, \\ 812, Japan
}

\begin{abstract}
Summary. Protection against experimental Serratia marcescens infection in mice was enhanced by prior injection of formalin-killed or viable bacteria of the same strain. From the first to the fourth week after vaccination, specific immunity was involved in the host defence against systemic serratia infection. The transfer of antiserum specific for $S$. marcescens increased bacterial clearance from the liver, but did not increase the survival of the mice. Bacterial clearance from the liver was also increased by the transfer of spleen cells from immunised mice, but, again, survival was not increased. However, the transfer of both antiserum and spleen cells from vaccinated mice increased both bacterial clearance from the liver and survival $(p<0 \cdot 01)$. These results suggest an additive effect of humoral immunity and T-cell-mediated immunity in protection against systemic serratia infection.
\end{abstract}

\section{Introduction}

Serratia marcescens is one of the most important aerobic gram-negative rods (GNR) causing urinary tract infection, ${ }^{1}$ pneumonia, ${ }^{2}$ septicaemia ${ }^{3}$ and meningitis, ${ }^{4}$ especially in immuno-compromised hosts. However, host defence mechanisms against systemic serratia infection are not fully understood.

We have studied specific and non-specific immunity to systemic serratia infection in an experimental mouse model. ${ }^{5}$ In the early phase after vaccination (within 7 days), enhancement of host defence mechanisms depends on phagocytic function and is nonspecifically activated by vaccination with dead bacteria. In the later phase (1-4 weeks after vaccination), specific immunity is thought to be involved. It has been suggested that immunity to $S$. marcescens infection is mediated by antibodies in that specific $\mathrm{O}$ antiserum against $S$. marcescens provided protection against peritoneal infection by the same O-type strain. ${ }^{6}$ However, in other pyogenic infections, both T-cells and a combination of cell-mediated and humoral immunity have been implicated in protection. For example, Tsuda et al. reported that T-cell-mediated immunity (CMI) contributed to resistance against staphylococcal infection in nude mice, ${ }^{7}$ whereas Akeda et al. reported a synergic contribution of macrophages and antibodies in protection against Salmonella typhimurium. ${ }^{8}$

To clarify the contribution of different host defence mechanisms against systemic serratia infection, we have examined the roles of humoral immunity, CMI and the combination of humoral immunity and CMI in resistance to systemic serratia infection.

\section{Materials and methods}

\section{Bacterial strains}

$S$. marcescens O-serotype $3(\mathrm{O}-3)$ was isolated from the blood of a patient suffering from septicaemia originating from urinary tract infection. Escherichia coli was also obtained from a clinical specimen. Each organism was passaged in ddY mice before use; briefly, organisms were inoculated intravenously (i.v.) into a ddY mouse, and fresh isolates were obtained from the spleen on the following day. The bacteria were then grown overnight on nutrient-agar plates at $37^{\circ} \mathrm{C}$. Colonies were suspended in sterile phosphatebuffered saline (PBS, $\mathrm{pH}$ 7.2) and again inoculated i.v. to a ddY mouse. After three such passages, the bacteria were grown in Trypto-Soy Broth (Eiken Chemical Co., Tokyo, Japan) with shaking for $16 \mathrm{~h}$ at $37^{\circ} \mathrm{C}$, washed three times with PBS and stored at $-80^{\circ} \mathrm{C}$. Formalin-killed bacteria were prepared by adding formalin to a final concentration of $0.5 \% \mathrm{v} / \mathrm{v}$ at room temperature. The killed bacteria were washed three times in sterile PBS and then suspended at a concentration of approximately $1 \times 10^{10} / \mathrm{ml}$ in sterile PBS.

\section{Animals and experimental infection}

Male ddY mice and BALB/c mice, aged 7-12 weeks, were purchased from the Kyudo Co. Ltd, Kumamoto, Japan. BALB/c mice were used for experiments involving spleen cell transfer. Mice were infected by i.v. injection of $S$. marcescens, and the LD50 and survival of mice were calculated by probit analysis. ${ }^{9}$ These experiments were repeated three to five times. 


\section{Immunisation procedure}

Mice were immunised by i.v. injection of $1 \times 10^{8}$ formalin-killed $S$. marcescens or $E$. coli cells, or by i.v. injection of $5 \times 10^{7}$ viable $S$. marcescens cells.

\section{Preparation of antiserum and passive immunisation}

Mice immunised with formalin-killed $S$. marcescens were given a booster injection of the same dose 7 days later. After a further 7 days, the mice were bled and their sera pooled. The antibody titre of the serum was determined by bacterial agglutination with formalinkilled bacteria. Passive immunisation of mice against $S$. marcescens was by i.v. injection of $1 \mathrm{ml}$ of this antiserum.

\section{Delayed foot-pad reaction}

Mice were immunised with formalin-killed $S$. marcescens or E. coli cells. After 2 weeks, $0.05 \mathrm{ml}$ of PBS containing $1 \times 10^{7}$ cells of formalin-killed $S$. marcescens was injected into their left hind foot-pads, and an equal amount of PBS into their right hind footpads. After $24 \mathrm{~h}$, the thickness of the foot-pads was measured with a dial thickness gauge. The delayed foot-pad reaction (DFR) was calculated as the thickness of the left foot-pad minus the thickness of the right foot-pad; a difference of $0.1 \mathrm{~mm}$ was defined as 1 unit.

\section{Spleen cell transfer}

BALB/c mice were immunised with formalin-killed $S$. marcescens; spleens were removed under sterile conditions, and spleen cells were obtained by crushing between two sterile glass slides. After filtering the crushed splenic tissue through two pieces of sterile gauze, spleen cells were suspended in $3 \mathrm{ml}$ of Eagle's Minimum Essential Medium (MEM, pH 7.4). The cells were washed twice with PBS, resuspended in MEM (without phenol red and containing $5 \mathrm{~mm}$ HEPES buffer, $\mathrm{pH} 7.4$ ) and incubated in petri dishes (Falcon, Oxnard, CA, USA) for $1 \mathrm{~h}$ at $37^{\circ} \mathrm{C}$ in a humidified atmosphere of $\mathrm{CO}_{2} 5 \%$ in air. Nonadherent cells were collected, and these procedures were repeated twice. One ml containing $1 \times 10^{8}$ nonadherent spleen cells was then injected i.v.; $1 \mathrm{~h}$ later, the animals were challenged by i.v. injection of viable $S$. marcescens, and bacterial counts on the liver were carried out 12 and $24 \mathrm{~h}$ after inoculation. In the second experiment, $0.5 \mathrm{ml}$ of antiserum from BALB/c mice was injected i.v.; spleen cells were transferred $1 \mathrm{~h}$ later, and the animals were challenged with viable $S$. marcescens $1 \mathrm{~h}$ after the spleen cell transfer.

\section{Bacterial counts on the livers of infected mice}

At various intervals after injection, animals were bled by severing the carotid artery. The liver was immediately removed and homogenised in $10 \mathrm{ml}$ of PBS. Serial 10-fold dilutions of the homogenate were made in PBS, and a $0 \cdot 1-\mathrm{ml}$ sample of each dilution was spread on nutrient agar. Colonies were counted after incubation for $20 \mathrm{~h}$ at $37^{\circ} \mathrm{C}$.

\section{Statistical analysis}

The statistical significance of the data was determined by Student's $t$ test.

\section{Results}

The effect of vaccination on i.v. infection with $S$. marcescens

The LD50 of $S$. marcescens at various time intervals after i.v. vaccination with viable or formalin-killed $S$. marcescens, or with formalin-killed $E$. coli, are shown in fig. 1. The LD50 in animals vaccinated with viable $S$. marcescens was $3 \times 10^{9}$ bacteria/mouse (about eight times higher than the LD50 in the control group) on day 7 after vaccination, decreasing to $9.5 \times 10^{8}$ bacteria on day 28 . This LD50 curve was not significantly different from that obtained after vaccination with formalin-killed $S$. marcescens. The LD50 of $S$. marcescens in the groups vaccinated with formalin-killed $E$. coli was significantly lower than in the groups vaccinated with viable or formalin-killed S. marcescens on days 7, 14 and 28 after vaccination. Thus, a specific component in the immunity against $S$. marcescens infection was identified from 7 days after vaccination, and was still apparent after 4 weeks. In subsequent experiments, formalin-killed $S$. marcescens were used for immunisation because there was no significant difference between the LD50 after vaccination with viable and formalin-killed organisms.

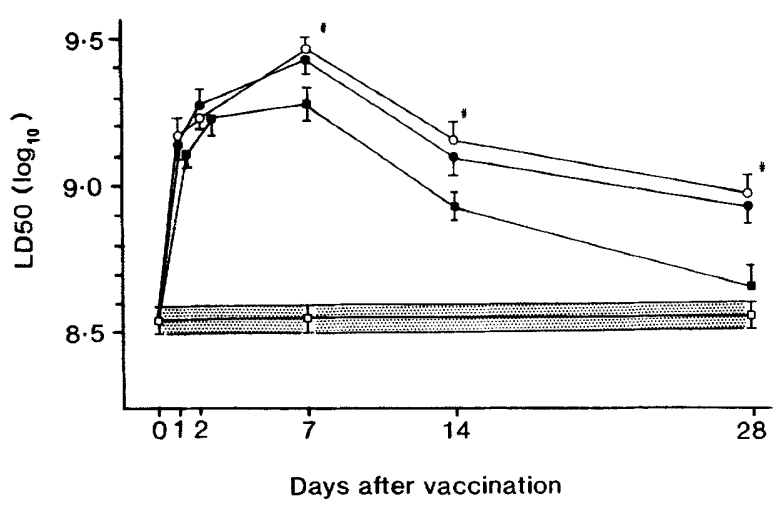

Fig. 1. The LD50 of $S$. marcescens after i.v. infection of mice vaccinated with $5 \times 10^{7}$ viable $S$. marcescens $0-3(\mathrm{O}), 1 \times 10^{8}$ formalin-killed $S$. marcescens O-3 (O), or $1 \times 10^{8}$ formalin-killed $E$. coli ( $\square)$. The shaded area shows the LD50 value of unvaccinated controls. These experiments were repeated 3-5 times; bars represent SEM ; \#, p < 0.05 compared with $E$. coli-vaccinated group. 


\section{The effect of transfer of antiserum on bacterial counts in the liver}

In previous studies, survival of mice infected with $S$. marcescens was not increased by transfer of specific antiserum. ${ }^{5}$ Therefore, bacterial counts in the livers of mice which had received specific antiserum were analysed. High-titre mouse antiserum (512 in the agglutination test) against $S$. marcescens was administered i.v. $(1 \mathrm{ml})$ to normal mice $1 \mathrm{~h}$ before i.v. infection with the same strain. After injection, the serum of the recipient mice had an anti-S. marcescens antibody titre of 64 . Fig. 2 shows that there was no significant difference in bacterial counts between mice that received antiserum and control mice that had received normal mouse serum.

\section{Induction of CMI as assessed by the foot-pad swelling test}

The foot-pad reaction of mice immunised with viable or killed $S$. marcescens, or with killed $E$. coli, was measured $24 \mathrm{~h}$ after inoculation of $S$. marcescens into the mouse foot-pad (fig. 3). Foot-pad swelling was significantly greater in mice immunised with $S$. marcescens than in those immunised with killed $E$. coli or non-immunised control mice, suggesting that a specific CMI response had been induced.

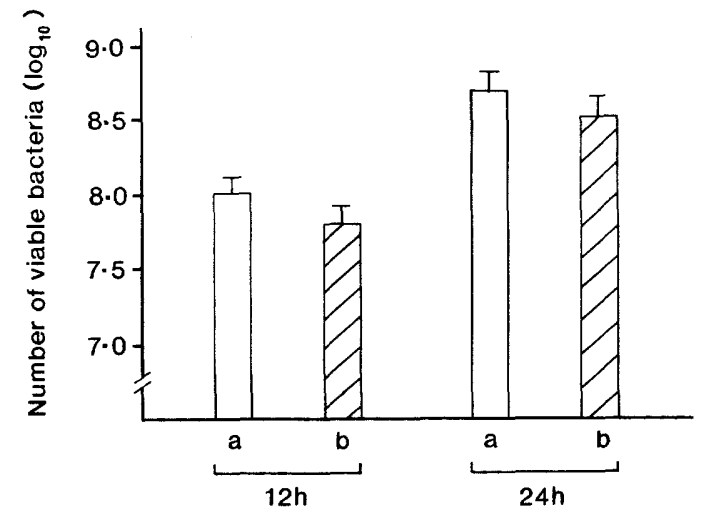

Fig. 2. Viable counts of bacteria in the livers of mice 12 and $24 \mathrm{~h}$ after i.v. infection with 7.6 $\times 10^{8}$ viable $S$. marcescens. Mice received either (a) normal serum or (b) antiserum. Bars represent SEM of five mice.

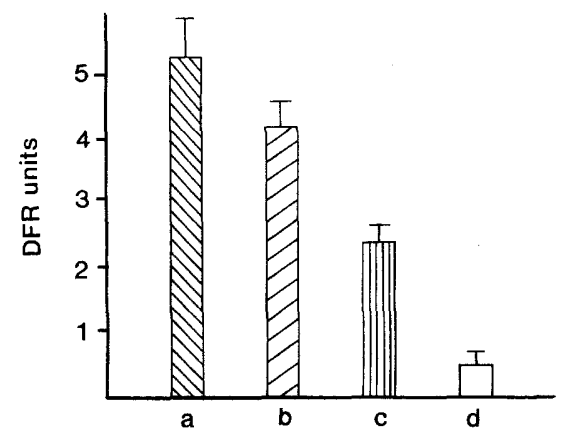

Fig. 3. Delayed foot-pad reaction in mice vaccinated with (a) viable $S$. marcescens, (b) formalin-killed $S$. marcescens or (c) formalinkilled $E$. coli, or (d) in unvaccinated control mice. Bars represent SEM of 10 mice.
The effect of transfer of antiserum and spleen cells on bacterial counts in the liver and on mouse survival

To evaluate the contribution of CMI and humoral immunity against systemic serratia infection, bacterial growth in the liver of unvaccinated BALB/c mice was compared following transfer of non-adherent spleen cells and antiserum from vaccinated BALB/c mice. Fig. 4 shows the bacterial counts in the liver of recipients of both serum and spleen cells from unvaccinated 'or vaccinated mice after i.v. infection with $6.2 \times 10^{8}$ viable $S$. marcescens cells $(c .1 .5$ LD50 in control mice); $12 \mathrm{~h}$ after infection, counts in the liver of the group receiving immune spleen cells were significantly lower than in those receiving control spleen cells. However, $24 \mathrm{~h}$ after infection no significant difference was observed. The bacterial counts in the livers of mice that had received both antiserum and immune spleen cells were lower than in those that had received immune spleen cells alone; however, the differences at both 12 and $24 \mathrm{~h}$ were not significant. The percentages of mice surviving after infection with various doses of viable bacteria, and transfer of either immune or non-immune spleen cells, are shown in table I. There was no difference between the group that received immune cells and the group that received non-immune cells. However, the survival of mice that received both antiserum and immune spleen cells was greater than those that received control (non-immune) serum and spleen cells (table II). These results suggest that transfer of both antiserum and immune spleen cells to normal mice was more effective in conferring resistance to i.v. infection with $S$. marcescens than transfer of antiserum or immune spleen cells alone.

\section{Discussion}

Bacterial infections have been categorised into two types on the basis of the host's response to infection. ${ }^{10}$

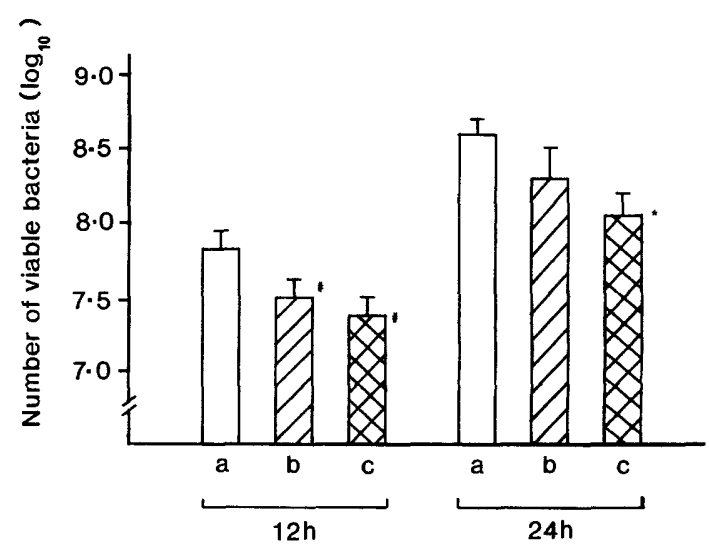

Fig. 4. Viable counts of bacteria in the livers of mice 12 and $24 \mathrm{~h}$ after i.v. infection with $6.2 \times 10^{8}$ viable $S$. marcescens. (a) Control mice received non-immune serum and spleen cells. Experimental mice received either (b) immune spleen cells alone, or (c) immune antiserum and immune spleen cells. Bars represent SEM of five mice; \# and *, p < 0.05 compared with non-immunised group. 
Table I. The effect of spleen cell transfer on resistance to i.v. infection by $S$. marcescens $0-3^{*}$

\begin{tabular}{clcr}
\hline $\begin{array}{c}\text { Infecting dose } \\
\text { (cells/mouse) }\end{array}$ & $\begin{array}{c}\text { Spleen cells } \\
\text { administered }\end{array}$ & $\begin{array}{c}\text { Number of survivors } \\
\text { /Number of mice }\end{array}$ & $\begin{array}{c}\text { Survival } \\
(\%)\end{array}$ \\
\hline \multirow{2}{*}{$9 \cdot 4 \times 10^{8}$} & Immune & $0 / 10$ & 0 \\
& Non-immune & $0 / 10$ & 0 \\
$4.7 \times 10^{8}$ & Immune & $5 / 10$ & 50 \\
& Non-immune & $4 / 10$ & 40 \\
& Immune & $10 / 10$ & 100 \\
& Non-immune & $9 / 10$ & 90 \\
\hline
\end{tabular}

* Normal recipient mice were given $1 \mathrm{ml}$ of $1 \times 10^{8}$ spleen cells from immunised or nonimmunised mice by i.v. injection 1 h before i.v. infection with $S$. marcescens $O-3$. The number of survivors was counted 7 days after infection; the data represent three experiments.

Table II. The effect of antiserum and spleen cell transfer on resistance to i.v. infection by $S$. marcescens $\mathrm{O}-3^{*}$

\begin{tabular}{clrr}
\hline $\begin{array}{c}\text { Infecting dose } \\
\text { (cells/mouse) }\end{array}$ & $\begin{array}{l}\text { Serum and spleen } \\
\text { cells administered }\end{array}$ & $\begin{array}{c}\text { Number of survivors } \\
\text { /Number of mice }\end{array}$ & $\begin{array}{c}\text { Survival } \\
(\%)\end{array}$ \\
\hline $1.5 \times 10^{9}$ & Immune & $2 / 10$ & 20 \\
& Non-immune & $0 / 10$ & 0 \\
$7.3 \times 10^{8}$ & Immune & $10 / 10$ & 100 \\
$3.7 \times 10^{8}$ & Non-immune & $1 / 10$ & 10 \\
& Immune & $10 / 10$ & 100 \\
& Non-immune & $5 / 10$ & 50
\end{tabular}

* Normal recipient mice were given $0.5 \mathrm{ml}$ of mouse antiserum (titre 32 in agglutination test) against $S$. marcescens $\mathrm{O}-3$ or normal mouse serum by i.v. injection 2 h before i.v. infection with $S$. marcescens $0-3$, and $1 \mathrm{ml}$ of $1 \times 10^{8}$ spleen cells from immunised or non-immunised mice $1 \mathrm{~h}$ before i.v. infection of the same strain. The number of survivors was counted 7 days after infection. These data represent three experiments.

Bacteria that cause purulent infections or cause infections in neutropenic patients are categorised as facultative extracellular bacteria; this category includes cocci as well as the gram-negative rods found in many kinds of infections. ${ }^{11}$ Bacteria that cause granulomatous infections or infections in CMI-impaired patients are categorised as facultative intracellular bacteria; this category includes Mycobacterium spp., Brucella spp., Listeria monocytogenes, Yersinia enterocolitica and Legionella pneumophila. ${ }^{12-15} \mathrm{~S}$. marcescens was categorised as an extracellular bacterium by Hahn et al. ${ }^{10}$ In extracellular bacterial infections, opsonising antibodies exert a protective effect, and usually the disease subsides after polymorphonuclear leucocytes and mononuclear phagocytes have phagocytosed most of the infecting bacteria. ${ }^{10,16-18}$

In our experiments, transfer of specific antibody did not increase the survival of mice with a systemic $S$. marcescens infection. ${ }^{5}$ The numbers of viable bacteria in the livers of mice that received specific antibodies were lower 12 and $24 \mathrm{~h}$ after i.v. infection with $S$. marcescens, but the differences were not significant $(p>0 \cdot 1)$ (fig. 2). Because antiserum was not very effective in protecting against systemic serratia infection, we examined the protective effect of cellmediated mechanisms. The induction of a cell- mediated response was demonstrated by the delayed foot-pad response test. ${ }^{19-22}$ Generally, immunisation with live bacteria induces protective immunity and delayed hypersensitivity, whereas immunisation with killed organisms or culture filtrates containing surface antigens does not. ${ }^{23-26}$ Our results (fig. 1) suggest that immunisation with either viable or killed $S$. marcescens generated specific CMI, as assessed by the delayed foot-pad response.

Growth of $S$. marcescens in the liver $12 \mathrm{~h}$ after i.v. infection was significantly $(\mathrm{p}<0.01)$ suppressed by the transfer of non-adherent spleen cells from mice immunised with $S$. marcescens (fig. 4). This suggests that activated $T$-cells produce lymphokines that activate tissue macrophages, resulting in enhanced host resistance. Patients with impaired CMI frequently develop infections with gram-negative rods such as Pseudomonas aeruginosa, Klebsiella pneumoniae, E. coli, S. marcescens, Proteus mirabilis, Enterobacter cloacae etc. ${ }^{27-32}$ Defective CMI is characterised by decreased delayed cutaneous hypersensitivity, decreased lymphocyte transformation by phytohaemagglutinin (PHA), and a decrease in the number of $\mathrm{T}$ cells. $^{20,27,32}$ Our data, showing that CMI is effective against systemic serratia infection, support these clinical findings. However, we were unable to demon- 
strate any increase in survival in recipients of immune spleen cells (table I). Therefore, we tested the simultaneous transfer of both antiserum and immune spleen cells to recipient mice. Bacterial growth in the livers of these mice was lower than in mice that received immune spleen cells alone (fig. 4). Moreover, the survival of mice that received both antiserum and immune spleen cells was clearly greater than that of mice that received immune spleen cells alone.

Our results suggest that specific antibody serves as an opsonin, facilitating the uptake of invading microorganisms by circulating or tissue phagocytes, and that immune T-cells activate the phagocytic and

\section{References}

1. Maki DG, Hennekens CG, Phillips CW, Shaw WV, Bennett JV. Nosocomial urinary tract infection with Serratia marcescens: an epidemiologic study. J Infect Dis 1973;128: 579-587.

2. Balikian JP, Herman PG, Godleski JJ. Serratia pneumonia. Radiology 1980; 137: 309-311.

3. Bosch JA, Vilaseca M, Fernandez F et al. Sepsis caused by Serratia marcescens. Report of 19 cases. Rev Clin Esp 1979 155: 93-96.

4. Sautter RL, Mattman LH, Legaspi RC. Serratia marcescens meningitis associated with a contaminated benzalkonium chloride solution. Infect Control 1984; 5: 223-225.

5. Kumagai Y, Okada K, Ishimaru T, Sawae Y, Kuroiwa A, Nomoto $K$. Effects of vaccination against systemic Serratic infection. J Clin Lab Immunol 1989; 29: 125-132

6. Simberkoff MS, Moldover NH, Rahal JJ. Specific and nonspecific immunity to Serratia marcescens infection. $J$ Infect Dis 1976; 134: 348-353.

7. Tsuda S, Sasai $Y$, Minami K, Nomoto $K$. Contribution of $T$ cell-mediated immunity to the resistance to staphylococcal infection. J Invest Dermatol 1978; 70: 345-347.

8. Akeda H, Mitsuyama M, Tatsukawa $K$, Nomoto $K$, Takeya $K$. The synergistic contribution of macrophages and antibody to protection against Salmonella typhimurium during the early phase of infection. J Gen Microbiol 1981; 123: 209214

9. Finney DJ. Probit analysis. A statistical treatment of the sigmoid response curve. Cambridge, Cambridge University Press. 1952

10. Hahn H, Kaufmann SHE. The role of cell-mediated immunity in bacterial infections. Rev Infect Dis 1981 ; 3: 1221-1250.

11. Klastersky J. Infections in immuno-compromised patients. I. Pathogenesis, etiology, and diagnosis. Clin Ther 1985; 8 . 90-99.

12. Carter PB. Pathogenicity of Yersinia enterocolitica for mice. Infect Immun 1975; 11: 164-170.

13. Horwitz MA, Silverstein SC. Legionnaires' disease bacterium (Legionella pneumophila) multiplies intracellularly in human monocytes. J Clin Invest 1980; 66 : 441-450.

14. World Health Organization Scientific Group. Cell-mediated immunity and resistance to infection. WHO Technical Report Series 1973; 519: 6-64.

15. Zinkernagel RM. Review: Cellular immune responses to intracellular parasites: role of the major histocompatibility gene complex and thymus in determining immune responsiveness and susceptibility to disease. Parasite Immunol 1979; 1: 91-109. microbicidal functions of macrophages in the liver and other reticulo-endothelial organs. Enhanced protection against bacterial growth in the liver and the increase in survival seen following the transfer of both antiserum and immune spleen cells suggest an additive effect of humoral and cell-mediated immunity in conferring protection against systemic serratia infection.

We thank Dr Y. Niho, Professor of the First Department of Internal Medicine, Faculty of Medicine, Kyushu University, for his careful reading of our manuscript and Dr A. Kuroiwa, Assistant professor of Department of Microbiology, School of Medicine Fukuoka University, for his excellent technical suggestions.

16. Fukutome T, Mitsuyama M, Takeya K, Nomoto K. Importance of antiserum and phagocytic cells in the protection of mice against infection by Klebsiella pneumoniae. J Gen Microbiol $1980 ; 119: 225-229$.

17. Ogata N. Analysis of protective mechanisms against infection by Pseudomonas aeruginosa: the synergistic contribution of polymorphonuclear leucocytes and antibody. Fukuoka Igaku Zasshi 1983; 74 : 335-350 (in Japanese).

18. Tsuru S, Nomoto K, Mitsuyama M, Zinnaka Y, Takeya K. Importance of polymorphonuclear leucocytes in protection of mice against Escherichia coli. J Gen Microbiol 1981; 122 335-338.

19. Kearn RJ, Hinrichs DJ. Kinetics and maintenance of acquired resistance in mice to Listeria monocytogenes. Infect Immun 1977; 16: 923-927.

20. Lane FC, Unanue ER. Requirement of thymus (T) lymphocytes for resistance to listeriosis. J Exp Med 1972; 135: 11041112 .

21. Mackaness GB. The influence of immunologically committed lymphoid cells on macrophage activity in vivo. J Exp Med 1969; 129: 973-992.

22. Mitsuyama M, Nomoto K, Akeda H, Takeya K. Enhanced elimination of Listeria monocytogenes at the site of delayed foot-pad reaction. Infect Immun 1980; 30: 1-4.

23. Hobson D. Resistance to reinfection in experimental mouse typhoid. J Hyg 1957; 55: 334-343.

24. Holland JJ, Pickett MJ. A cellular basis of immunity in experimental Brucella infection. J Exp Med 1958; 108: 343-360.

25. Mackaness GB. Cellular resistance to infection. $J$ Exp Med 1962; 116: 381-406.

26. Stableforth AW. Brucellosis. In: Stableforth AW, Galloway IA (eds) Infectious disease of animals, vol 1. London, Butterworths Scientific Publications. 1959: 53-159.

27. Carney JM, Warne MS, Borut T et al. Cell-mediated immune defects and infection. Am J Dis Child 1980; 134: 824-827.

28. George CD, Morello PJ. Immunologic effects of blood transfusion upon renal transplantation, tumor operations, and bacterial infections. Am J Surg 1986; 152: 329-337.

29. Clumeck N, George C. Immunological aspects of severe bacterial sepsis. Intensive Care Med 1981; 7: 109-114.

30. Miedema F, Tetteroo PAT, Terpstra FG et al. Immunologic studies with LFA-1- and Mol-deficient lymphocytes from a patient with recurrent bacterial infections. $J$ Immunol $1985 ; 134$ : 3075-3081.

31. Petersen PK. Host defense abnormalities predisposing the patient to infection. Am J Med 1984; 76 (5A): $2-10$

32. Sorensen RU, Stern RC, Chase P, Polmar SH. Defective cellular immunity to gram-negative bacteria in cystic fibrosis patients. Infect Immun 1979; 23: 398-402. 